\title{
Genética textual a partir de fragmentos: una página y media del manuscrito de «Abenjacán el Bojarí, muerto en su laberinto" y otros enigmas
}

\author{
Daniel Balderston ${ }^{\bullet}$ \\ University of Pittsburgh
}

\section{Resumen}

El cuento de Borges «Abenjacán el Bojarí, muerto en su laberinto» fue publicado en Sur en 1951 y luego incluido en la segunda edición de El Aleph en 1952. El sobrino de Borges, Miguel de Torre Borges, publicó el fragmento final de ese manuscrito en su libro de fotografías y manuscritos de su tío. Ese fragmento se estudia aquí en detalle, utilizando las herramientas de la crítica genética, en la línea de How Borges Wrote (2018).

\author{
Palabras claves \\ - Borges · Manuscritos · Crítica genética · Sur - El Aleph
}

\begin{abstract}
The Borges's story «Ibn-Hakam al-Bokhari, Murdered in His Labyrinth» was first published in magazine Sur in 1951 and included in the second edition of El Aleph in 1952. Borges's nephew Miguel de Torre Borges published the final page and a half of the manuscript of the story in his book of family photographs and manuscripts. That fragment is studied here in depth using the techniques of genetic criticism, along the lines explored in How Borges Wrote (2018).
\end{abstract}

\section{Keywords}

· Borges · Manuscripts · Genetic Criticism · Sur · El Aleph

\footnotetext{
- Ph.D. en Literatura Comparada, Princeton, 1981. Actualmente es el Andrew W. Mellon Professor of Modern Languages en la Universidad de Pittsburgh. Dirige el Borges Center y la revista Variaciones Borges. Sus libros más recientes son How Borges Wrote (2018), de próxima aparición en español en Ediciones Ampersand, y Los caminos del afecto (2015). Eduvim publicará pronto Leído primero y escrito después, sobre Roa Bastos, Piglia y Saer.
} 
En varias ocasiones Borges reescribe de las Mil y una noches de Burton la «historia de los dos que sońaron»: un cuento en que alguien sueńa con un tesoro enterrado bajo un puente en un pueblo lejano, viaja hasta el puente, se encuentra con alguien que le pregunta qué está buscando bajo el puente, y cuando se lo explica dice que no hay que preocuparse por los sueños porque si él lo hubiera hecho hubiera ido al fondo de un jardín en un pueblo lejano donde hubiera encontrado un tesoro; el primero regresa a su casa y desentierra el tesoro en su propio jardín. (Hay versiones en otras culturas; Martin Buber recoge una versión judía en sus Cuentos jasídicos.) Me siento un poco así, después de haber trabajado doce años para encontrar y cotejar manuscritos de Borges, e incluso después de haber estudiado un pequeño detalle del que voy a comentar hoy - la anotación marginal sobre estudiosos de Dante- en How Borges Wrote (y en algunos ensayos que lo antecedieron). En el libro no trabajé la página y media del manuscrito de «Abenjacán el Bojarí, muerto en su laberinto" que se reproducen en las dos ediciones del libro de Miguel de Torre Borges, Borges, manuscritos y fotografias (1987) y Borges, fotos y manuscritos (2005), supongo que porque era solo un fragmento, porque ya tenía acceso a muchos otros materiales, porque quería cotejar más de una versión de un texto, porque era de acceso fácil, qué sé yo, pero el hecho es que no lo trabajé. Lo hago ahora como muestra de lo que dejé de lado, como dejé de lado muchísimos otros manuscritos de Borges que se pueden estudiar de modo riguroso con las herramientas de la crítica genética.

Vale la pena aclarar que no sé dónde está el manuscrito en cuestión, y que por ende no he visto las páginas iniciales. El fragmento que publicó de Torre comienza: «— No —dijo Unwin con seriedad», es decir, al final de la página 604 de las Obras completas de 1974: la página y media que publicó de Torre corresponde a lo que está desde el final de esa página 605 y parte de la página 606, es decir que faltarían más o menos las primeras siete páginas del manuscrito. Un misterio más, entonces, es por qué Borges enumera estas dos páginas «17» y «18», ya que no pueden haber existido quince páginas anteriores a estas dos. Si alguien sabe dónde están podríamos resolver ese pequeño enigma. Pero hay suficiente material en esa página y media para ocuparnos hoy.

El cuento, como ustedes recordarán, es un relato policial clásico: Dunraven el poeta y Unwin el matemático llegan al lugar de los hechos, en un acantilado cerca de un pueblo de Cornwall, años después de un triple asesinato. Dunraven cuenta la historia, dando por supuesto que ya se sabe la solución; Unwin lo escucha atentamente, le hace unas preguntas, y al final propone otra solución. Es decir, corresponde al modelo del armchair detective representado por el Auguste Dupin de Poe y el Sherlock Holmes de Conan Doyle (entre muchos otros ejemplos), y sigue muy de cerca las pautas de ese tipo de cuento policial analítico, más cerca (de hecho) que los otros cuentos policiales de Borges («Hombre de la esquina rosada», "Emma Zunz», "La muerte y la brújula», "El jardín de senderos que se bifurcan», "El muerto», para dar algunos ejemplos, en todos los cuales Borges 
invierte el paradigma clásico al narrar el crimen y no la investigación). En este caso, además, hay referencias explícitas a esa tradición: Unwin le dice a su amigo, «No multipliques los misterios [...]. Estos deben ser simples. Recuerda la carta robada de Poe, recuerda el cuarto cerrado de Zangwill. O complejos — replicó Dunraven-. Recuerda el universo" (600). Lo irónico aquí es que Unwin tiene razón con respecto a la estructura del cuento policial clásico (y propondrá una solución convincente acorde con esa tradición) pero Dunraven tiene cierta razón con respecto a los misterios del mundo: los dos amigos están en Cornwall en «la última tarde del verano de 1914 [y estaban] hartos de un mundo sin la dignidad del peligro" (1974:600): el archiduque Francisco Fernando de Austria será asesinado una semana después, un hecho que provocará el comienzo de la Gran Guerra. Borges, como siempre, está atento a los detalles micro y marco: nada dice sobre el destino de los amigos, pero queda a cargo del lector imaginarlos poco después en los campos de batalla del norte de Francia o en Bélgica. Y las consecuencias del asesinato hecho por Gavrilo Princip siguen siendo misteriosas, como atestiguan miles de páginas de los historiadores.

El fragmento del manuscrito publicado por el sobrino comienza con una discusión del laberinto de Creta y del «hombre con cabeza de toro» que está en su centro. El narrador aclara:

Dunraven, versado en obras policiales, \{no podía ignorar que la solución siempre es inferior al enigma. + pensó que la solución del misterio siempre es inferior al misterio.\} El misterio participa de lo sobrenatural y aún de lo divino; la solución, del juego de manos. Dijo, para aplazar lo inevitable:

- Cabeza de toro tiene en medallas y esculturas el minotauro. Dante lo imaginó con cuerpo de toro y cabeza de hombre. Scartazini 93, Grabher I, 188, Flamini 172.

— También esa versión me conviene- Unwin asintió. — Lo que importa es la ominosa intima + secreta + honda correspondencia de la casa misteriosa con el habitante monstruoso. El minotauro justifica con creces la existencia del laberinto.

Hay dos cuestiones en juego en este fragmento: una reflexión teórica sobre el género policial, ya que la propuesta de Dunraven es «inferior al misterio» por depender "del juego de manos» (una magia barata). El otro asunto es si el Minotauro evocado por Unwin como «hombre con cabeza de toro» no es más bien lo contrario, como alega Dunraven: "Cabeza de toro tiene en medallas y esculturas el minotauro. Dante lo imaginó con cuerpo de toro y cabeza de hombre». La referencia es al canto duodécimo del Inferno donde la manera de correr del Minotauro indica que para Dante tiene cuerpo de toro y cabeza de hombre. La referencia marginal aquí — «Scartazzini 93, Grabher I, 188, Flamini 172»— se refiere a ediciones comentadas de la Divina Commedia. Grabher dice: «Dante, interpretando liberamente il semibovemque virum, semivirumque bovem di Ovidio [...] rappresenta il mostro col corpo di toro e la testa d'uomo, mentre in medaglie e sculture antiche appare como un uomo dalla testa di toro» (Dartmouth Dante Project). Scartazzini y Vandelli dicen: «Dante si figura il Minotauro come toro con testa d'uomo, interpretando liberamente il semibovemque virum, semivirumque bovem di Ovidio: le medaglie e le sculture antiche ci danno invece un uomo con testa di toro" (Dartmouth Dante Project) ${ }^{1}$. En ese momento Borges estaba estudiando de cerca el poema de Dante para la introducción a la edición de los Clásicos Jackson y una serie de 
artículos en La Nación (reunidos muchos años después como los Nueve ensayos dantescos), y sabemos que su biblioteca contenía múltiples ediciones de Dante y de sus comentaristas (otro ejemplo de la misma época está al comienzo del cuento «La espera» de 1950, donde se refiere a la edición comentada de Andreoli); no sorprende, por ende, que se refiera con mucha exactitud en la nota marginal del manuscrito a las discusiones en torno al Minotauro en los comentaristas de Dante. Otro detalle interesante: el manuscrito muestra que Borges estaba pensando en «ominosa correspondencia» $\mathrm{o}$ «íntima» $\mathrm{o}$ «secreta» $\mathrm{u}$ «honda» entre la casa misteriosa y su «habitante monstruoso»; en la versión publicada no se decide por ninguno de esos cuatro adjetivos, sino que prefiere una repetición de lo «monstruoso»: «lo que importa es la correspondencia de la casa monstruosa con el habitante monstruoso" (1974:605). Como he comentado en otra parte, Borges rechaza en la práctica la preferencia por la no repetición de palabras que regía en la época (piensen en la frase larga de «El Aleph»). Y la repetición de «monstruosa/monstruoso» aparece en boca de Dunraven, un poeta enfático si los hay.

El fragmento siguiente está a cargo mayormente de Unwin:

Nadie dirá lo de una amenaza proferida escuchada + percibida + escuthada en un sueńo. \{Sugerida + Evocada\} la imagen del minotauro (imagen evocación fatal casi inevitable en un caso en que hay un laberinto) el problema, virtualmente, estaba resuelto. Sin embargo, confieso que no entendí que esa antigua imagen era la clave y así fué necesario que tu relato me suministrara \{otro símbolo, el de la arańa. + un símbolo más preciso: la telaraña.\}

— ¿La telaraña? - repitió, perplejo, Dunraven.

- Sí. Nada me asombraría que la telaraña (la forma universal de la telaraña, la telaraña de Platón) hubiera sugerido al asesino (porque hay un asesino) su crimen. Recordarás que el Bojarí, en una tumba, sońó con una red de serpientes y que al despertar comprendió descubrió que una telaraña le había \{hecho soñar aquel sueño. + sugerido aquel sueño.\}

Las alternativas giran en torno, casi todas, a verbos: «escuchar» o "percibir» (escogerá «percibir»), «sugerir»o «evocar» (escogerá «evocar»), «comprender»o «descubrir» (escogerá «descubrir»): Borges quiere que Unwin haga hincapié en acciones mentales (percibir, evocar, descubrir), y que esas acciones tengan que ver con el problema intelectual de la relación entre particulares y generales (por eso la evocación de Platón). Recordemos que Unwin acaba de proponer un estudio del teorema perdido de Fermat, y por ende está seriamente interesado en los misterios de las series matemáticas; la solución final que propondrá al enigma de los tres cuerpos —el león, el esclavo y el rey o su primo—- depende de la posibilidad de abstraerse de los particulares para subrayar la estructura matemática de serie. El párrafo largo donde Unwin propone su versión continúa:

Volvamos a esa noche en que el Bojarí soñó con una red. El rey vencido y el visir y el esclavo huyen por el desierto con un tesoro. Se refugian en \{la tumba de un santo. + una tumba.\}

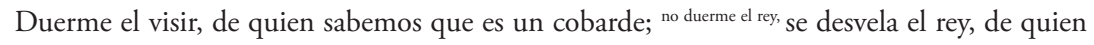
sabemos q. es un valiente. El rey, para no compartir el tesoro con el visir, lo mata de \{una puñalada en el sueño, + una cuchillada; noches después, su sombra lo su forma lo amenaza en un

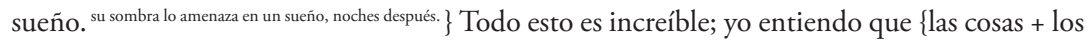
hechos\} ocurrieron de otra manera. 
Aquí las posibilidades divergen de nuevo: propone «la tumba de un santo» pero se queda con simplemente «una tumba» (por la ubicación de la acción en el norte de África el lector tal vez imagine una típica tumba de santo musulmana). En vez de «se desvela el rey» prefiere «no duerme el rey», una descripción más neutra. Pero el momento en que más pululan las posibilidades tiene que ver con la amenaza que representa la sombra de la víctima en las noches siguientes: «su sombra lo amenaza en un sueño" y "su forma lo amenaza en un sueño» se descartan para la versión definitiva, «su sombra lo amenaza en un sueńo, noches después» (la primera de las posibilidades se rescata, pero posterga «noches después» hasta el final de la oración). Caracteriza la intrusión de lo fantástico como algo «increíble» pero después, racionalista como es, dice que «las cosas» $\mathrm{o}$ «los hechos» (Borges preferirá después «hechos») ocurrieron de otro modo, no fantástico.

Continúa su razonamiento:

Durmió esa noche el rey, el valiente, y veló Zaid, el cobarde. Dormir es distraerse del universo y la distracción es difícil \{cuando sabemos que un ejército nos persigue. + para quien sabe que lo persiguen con espadas desnudas.\} Zaid, codicioso, ávido, se inclinó sobre el sueño de su señor. de su rey. Pensó en matarlo (quizá jugó con el puñal), pero no se atrevió. Llamó al esclavo,

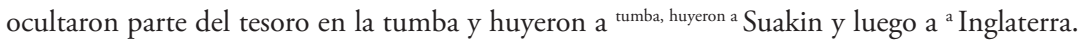
$\{$ En \{Pentreath erigió el laberinto, no para esconderse del Bojarí sino para atraerlo. + Inglaterra levantó el laberinto, el laberinto carmesí construido por un moro que andaba con un león y un esclavo, no para esconderse del Bojarí, sino para...\} + No para esconderse de Abenjacán ocultarse del Bojarí sino para atraerlo y matarlo, construyó a la vista del mar el alto laberinto de color rojo. muros rojos.\} Sabía que las naves llevarían a los puertos de Nubia la fama del hombre bermejo, del esclavo y del león, y que, tarde o temprano, \{Abenjacán vendría a buscarlo en su laberinto. + el Bojarí lo vendría a buscar en su laberinto.\}

Aquí se presentan alternativas radicalmente diferentes entre sí: «cuando sabemos que un ejército nos persigue» y "para quien sabe que lo persiguen con espadas desnudas» (la lectura definitiva será la segunda). También baraja dos posibilidades para la planificación del crimen: «esconderse del Bojarí» vs. «esconderse de Abenjacán», y "ocultarse» como alternativa a "esconderse»; la versión definitiva dirá "no para ocultarse del Bojarí», que no es ninguna de las alternativas aquí. Las otras alternativas son menores: «codicioso» vs. «ávido», «de su señor» vs. «de su rey», «el alto laberinto de color rojo» vs. «el alto laberinto de muros rojos», y algunos cambios menores de orden de palabras. Siguen los preparativos del crimen:

Sabía que las naves llevarían a los puertos de Nubia la fama del hombre bermejo, del esclavo y del león, y que, tarde o temprano, \{Abenjacán vendría a buscarlo en su laberinto. + el Bojarí lo vendría a buscar en su laberinto. ${ }^{\text {(En elúltimo... trampa.) }}$ En el último corredor \{lo esperaba la trampa sobre la curva de la escalera. + de la red lo esperaba la trampa.\}\{Sabía, quizá, que el Bojarí no tomaría la menor precaución porque lo despreciaba infinitamente. + El Bojarí lo despreciaba infinitamente; no se rebajaría a tomar la menor precaución. $\}$. \{ $\left\{{ }^{3}\right.$ El día codiciado llegó $+{ }^{1}$ Las vueltas de los años trajeron el día codiciado $+{ }^{2}$ Los años trajeron, al fin, el día codiciado\}; Abenjacán desembarcó en Inglaterra, caminó hasta la puerta del laberinto, barajó los ciegos corredores y ya había pisado, tal vez, los primeros peldaños \{de la escalera cuando Zaid lo mató, quizá de un balazo, desde la trampa. + cuando su visir lo mató, no sé si de un balazo, desde la trampa.\} 
Aquí la proliferación de posibilidades es más radical. Baraja muchas posibilidades a la vez: «Abenjacán vendría a buscarlo en su laberinto» o «el Bojarí lo vendría a buscar en su laberinto», «En el último corredor lo esperaba la trampa sobre la curva de la escalera» o «En el último corredor de la red lo esperaba la trampa» (las segundas opciones son las definitivas). Más importante aún, en la frase siguiente las alternativas giran en torno al conocimiento del primo de la psicología del rey: «Sabía, quizá, que el Bojarí no tomaría la menor precaución porque lo despreciaba infinitamente» vs. «El Bojarí lo despreciaba infinitamente; no se rebajaría a tomar la menor precaución». Luego, tres opciones para la llegada de Abenjacán: «El día codiciado llegó», «Las vueltas de los años trajeron el día codiciado», y «Los años trajeron, al fin, el día codiciado»; de esas tres, escoge la primera, la más simple. Y termina este pedazo con dos alternativas, en la segunda de las cuales se hace presente Unwin como narrador: «cuando Zaid lo mató, quizá de un balazo, desde la trampa» vs. "cuando su visir lo mató, no sé si de un balazo, desde la trampa»; la versión definitiva insistirá en la incertidumbre de Unwin, que elabora su versión de forma hipotética. (Habrán notado que también en este largo párrafo Borges vacila varias veces entre poner los nombres de los personajes — Abenjacán, Zaido referirse a ellos por sus títulos — rey o señor, visir.)

El párrafo concluye así:

El esclavo mataría el león y otro balazo mataría al esclavo. Luego Zaid deshizo las tres caras con una piedra. Tuvo que obrar así; un solo muerto con la cara deshecha hubiera sugerido inmediatamente un problema de identidad, pero \{el león, el esclavo y + la fiera, el negro y\} el rey formaban una serie y, dados los dos términos iniciales, \{todos aceptarían todos postularian + nadie dudaría del\} el último. No es raro que lo dominara el temor cuando habló con Allaby; acababa de $\left\{{ }^{2}\right.$ ejecutar $+{ }^{1}$ cumplir $\}$ la horrible faena y se disponía a huir de Inglaterra para recuperar el tesoro.

Aquí se unen el matemático Unwin y el estudiante de matemáticas Borges (que emplea muchas marcas de puntuación que tienen que ver con la lógica formal, como también lo hace en el manuscrito de «Viejo hábito argentino»o «Nuestro pobre individualismo»). Importa la precisión aquí: es «el león, el esclavo y el rey» o «la fiera, el negro y el rey» los que «formaban una serie y, dados los dos términos iniciales», dice, «todos aceptarán» o «todos postularían» o «nadie dudaría»; se queda con el verbo «postular» (que tiene más afinidades a la prueba matemática, pero que también recuerda su importante ensayo de 1931 «La postulación de la realidad»). Y propone dos posibilidades para resumir la acción: «ejecutar» $\mathrm{o}$ «cumplir» la horrible faena (se queda con «ejecutar», que tiene más que ver con el acto de asesinar y de mutilar los cuerpos).

Después viene una breve pausa, mientras Dunraven reflexiona sobre la hipótesis de su amigo: «Un silencio perplejo, o meditativo, siguió pensativo, o incrédulo, siguió a las palabras de Unwin. Dunraven pidió otra jarra de cerveza antes de opinar». De las dos alternativas posibles, "perplejo, o meditativo» o "pensativo, o incrédulo» se queda con la segunda: para retratar a Dunraven importa más lo «incrédulo» (que tiene que ver con su fe en una versión más poética) que lo «meditativo»; de todos modos Dunraven medita mientras Unwin piensa o razona.

Lo que sigue es la reflexión de Dunraven sobre la hipótesis: 
—Acepto- dijo — que mi Abenjacán era \{Zaid, que \{la presunta víctima era el verdadero culpable. + el matador era el muerto y el muerto el matador.\} + Zaid.\} Tales metamorfosis, me dirás, con artificios del género, son verdaderas convenciones cuya observación exige el lector. Lo que me resisto a admitir es \{tu conjetura de que una parte del tesoro quedó enterrada en Africa. + la conjetura de que una porción del tesoro quedara en el Sudán.\} Recuerda que Zaid huía del rey y de los enemigos del rey; \{no tenía tiempo que perder en esas maniobras. + más fácil es imaginarlo robándolo todo huyendo con todo el tesoro que demorándose a enterrar una parte.\}

De nuevo se insiste en la idea de que Dunraven está «versado en obras policiales», ya que aquí habla de las reglas del género (tan importantes para que el lector entre en el juego), reglas que Borges había discutido en 1936 en «Los laberintos policiales y Chesterton», y que seguiría discutiendo en muchas reseńas de novelas policiales en El Hogar (desde 1936 hasta 1939). Algunas alternativas aquí son menores — «el matador» vs. «Zaid» (de nuevo, rol vs. nombre), «quedó enterrada en África» vs. «quedara en el Sudán»— pero la última es significativa: «no tenía tiempo que perder en esas maniobras» versus «más fácil es imaginarlo huyendo con todo [o «robándolo todo»] el tesoro que demorándose a enterrar una parte»: de nuevo a Dunraven le interesa «imaginar», construir una intriga, más que el proceso de razonamiento de su amigo. Ese párrafo sigue con Dunraven:

No sé con precisión lo que costará construir un laberinto, \{lgnoro el costo de un laberinto, pero sospecho que los albañiles de Pentreath dieron cuenta de los seguíes del desierto. + A diferencia del oro rojo de los Nibelungos, q. era infinito, Carlyle, III, 125. los seguíes del desierto habrán tenido fin algún día, habían consumido habín agotado un caudal que, a diferencia del oro rojo de los Nibelungos, no era infinito.\} Tendríamos así a Abenjacán atravesando el mar para reclamar un tesoro \{que no existía.\} dilapidado.\}

Aquí Dunraven, que aspira a una poesía épica, piensa en el Nibelungenlied, en el famoso episodio del tesoro que no acaba. La referencia marginal de Borges remite a una página precisa del estudio de Thomas Carlyle:

They had brought out the Treasure from the cave where it usually lay; but how to part it was the difficulty; for, not to speak of gold, there were as many jewels 'as twelve wagons in four days and nights, each going three journeys, could carry away/' nay, 'however much you took from it, there was no diminution' (Carlyle, 1907:125).

En la discusión del tesoro enterrado en el Sudán hay diferencias notables entre esta versión y la publicada: en vez de la discusión intrincada sobre el costo de un laberinto y de la disminución de los «seguíes» del desierto, escribe después (en otra parte) una frase más sencilla: «Quizá no se encontraron monedas porque no quedaban monedas; los albañiles habrían agotado un caudal que, a diferencia del oro rojo de los Nibelungos, no era infinito» (1974:606). Piensa aclarar, pero después omite, la idea de que es un tesoro «que no existía».

Y aquí llegamos al trozo más interesante de este fragmento de manuscrito. Borges primero escribe, y luego tacha, la frase: «Y Zaid — dijo Unwin — fingiendo ser Abenjacán y convirtiéndolo al fin en Abenjacán, es decir, en un pordiosero». Esa versión bastante sencilla se tacha para reemplazarlo con el grandioso párrafo penúltimo del cuento: 
—Dilapidado, no- dijo Unwin - Invertido en armar en tierra de infieles una gran trampa circular de ladrillo destinada a apresarlo y a aniquilarlo. Zaid, si tu conjetura ${ }^{\text {es }\{\text { veraz + correcta\} no }}{ }^{\text {no }}$ se equivoca, procedió a impulsos del temor y del odio y no de la codicia; urgido por el odio y por el temor y no por la codicia. Robó el tesoro y luego comprendió que el tesoro no era lo esencial para él. \{La muerte de Abenjacán era lo esencial. + Lo esencial era que Abenjacán pereciera.\} Simuló ser Abenjacán, mató a Abenjacán y al fin se convirtió en Abenjacán finalmente fué Abenjacán, es decir un viejo mendigo.

Aquí se nota la proliferación de posibilidades que se ve en los manuscritos de Borges en sus mejores y más intensos momentos (la proliferación de seres en «El jardín de senderos que se bifurcan», las cosas vistas en el Aleph, la definición del «hecho estético» en «La muralla y los libros», para solo dar tres ejemplos): al descartar la idea de una simple sustitución de un personaje por otro, hay una serie de alternativas notables sobre las emociones que inspiran a Zaid (temor, odio, codicia), que se atribuyen a Dunraven («si tu conjetura es veraz» o "correcta»), para dar con otra solución, más radical. «\{La muerte de Abenjacán era lo esencial. + Lo esencial era que Abenjacán pereciera.\} Simuló ser Abenjacán, mató a Abenjacán y al fin se convirtió en Abenjacán finalmente fué Abenjacán, es decir un viejo mendigo». Esto se va a resumir en dos frases lapidarias en la versión final: «Lo esencial era que Abenjacán pereciera. Simuló ser Abenjacán, mató a Abenjacán y finalmente fue Abenjacán» (606).

$\mathrm{El}$ «es decir un viejo mendigo» se omite del discurso de Unwin para atribuírsele en seguida a Dunraven: «-Sí- completó Dunraven—. Sí- confirmó Fué un vagabundo que, antes de ser nadie en la muerte, recordaría haber sido un rey o haber fingido ser un rey, algún día». Es decir, la definición de Zaid como un «mendigo» (en el discurso tachado de Unwin) o como «vagabundo» (en la versión final, ahora atribuido a Dunraven), al cambiar de la voz del matemático a la del poeta, busca un efecto patético (de nuevo acorde con las aspiraciones poéticas de uno de los amigos). Unwin ya dijo lo esencial en el párrafo anterior, y Borges subraya sus palabras finales, "fué Abenjacán», para no dejar dudas acerca de sus ideas radicales sobre el motivo del doble. Así, asimila en un ser los dos personajes antagónicos, el rey y su visir y primo, el valiente y el cobarde, como había hecho en otros cuentos sobre dobles (pensemos en «Los teólogos», en «Historia del guerrero y de la cautiva», en "Tema del traidor y del héroe»). A la vez, hay una delicada asimilación de los dos amigos en Cornwall, "hartos de una vida sin la dignidad del peligro» (1974:600): la oposición que estructura el cuento es menos absoluta de lo que parece si la idea sobre la reducción de Zaid en «mendigo» o «vagabundo» se puede atribuir inicialmente a Unwin y después a Dunraven. Esa identificación parcial entre los dos obliga a mirar lo que viene justo antes del fragmento que tenemos de este manuscrito. Dunraven había recitado un par de versos de su autoría sobre el asunto ("Faceless the sultry and overpowering lion,/ Faceless the stricken slave, faceless the King» [1974:604]). Dunraven responde:

Un fugitivo no se oculta en un laberinto. No erige un laberinto sobre un alto lugar de la costa, un laberinto carmesí que avistan desde lejos los marineros. No precisa erigir un laberinto, cuando el universo ya lo es. Para quien verdaderamente quiere ocultarse, Londres es mejor laberinto que un mirador al que conducen todos los corredores de un edificio. La sabia reflexión que ahora te someto me fue deparada antenoche [sic] mientras oíamos llover sobre el 
laberinto y esperábamos que el sueño nos visitara; amonestado y mejorado por ella, opté por olvidar tus absurdidades y pensar en algo sensato. (Borges, 1974:604)

A ese ataque (tildar las aspiraciones poéticas de «absurdidades») responde Dunraven, molesto: «En la teoría de los conjuntos, digamos, o en una cuarta dimensión del espacio» (1974:604). Es decir, la parte que nos falta sería otra asimilación de los dos amigos en uno: Dunraven es el que nombra la teoría de los conjuntos, tratando de burlarse del amigo pero convirtiéndose en él (como le pasará a Zaid en la versión hipotética de Unwin). Los dos se necesitan para narrar la historia, como en el cuento policial clásico, pero Borges da una vuelta de tuerca al proponer que son dos caras de la misma moneda. Como dijo Sylvia Molloy en Las letras de Borges, la ficción de Borges

aprovecha esa coyuntura convencional y se detiene en ella para socavar la elemental organización a base de contrastes. Los textos narrativos de Borges, como pocos, fragmentan los elementos que los compondrían según una mímica dual; y también, como pocos, se permiten atribuir a esos fragmentos — personajes añicados, actos retaceados, textos aislados — la ilusión de un diálogo que por un momento parece atenerse a solo dos dialogantes pero que es, profundamente, un diálogo múltiple. (Borges, 1974:84)

Esa discusión del tratamiento del doble en Borges en el libro de Molloy lo continué yo en un capítulo de El precursor velado (1985/2019); en todo caso los modos en que Borges se sirve de los dobles son tan radicales como sus juegos con el género policial, buscando siempre finales abiertos, no cerrados.

El final del manuscrito contiene las últimas palabras de Dunraven sobre el caso (el poeta tiene la última palabra) y una anotación de Borges sobre el lugar y fecha de su composición: «Mar del Plata, 1948», tachado, y luego «Adrogué, 1949».

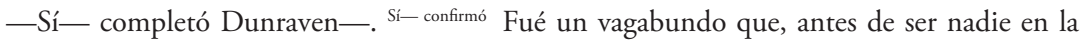
muerte, recordaría haber sido un rey o haber fingido ser un rey, algún día.

Mar del Plata, 1948.

Adrogué, 1949.

Como Borges a veces veraneaba en Villa Silvina en Mar del Plata, y 1948 es una época intensa de trabajo en colaboración con Bioy Casares sobre la ficción policial, imagino que comenzó allá, para terminar el relato un verano después en la casa que había comprado su madre en Adrogué en 1944 (y que vendería en 1952). Es un cuento sobre el verano de 1914 (un momento cargado de significación histórica) escrito en los veranos de 1948 y 1949 (también momentos de gran tensión política para Borges, y en la víspera de su gran carrera de conferencista (y luego docente). Si se examina el sitio web que hizo Mariela Blanco con un equipo en la Universidad Nacional de Mar del Plata se nota una serie de conferencias y clases sobre la ficción policial que comienzan en 1949 y se extienden hasta la ceguera, para retomarse años después en varias de las célebres series de conferencias recogidas en libro.

La frase final de Dunraven ofrece solo un resumen, un poco más enfático, de la versión propuesta por Unwin, pero recalca el dramatismo de la muerte: «antes de ser nadie en la muerte, recordaría haber sido un rey o haber fingido ser un rey, algún día». El relato termina, entonces, con una prolepsis al momento de la muer- 
te de Zaid, y ese desplazamiento temporal puede sugerirle al lector la necesidad de pensar en los momentos de las muertes de Dunraven y Unwin, tal vez en las trincheras del Somme en 1916 (tema, como ya sabemos, de «El jardín de senderos que se bifurcan», otro texto clave en la serie de ficciones policiales de Borges).

Por ser apenas un fragmento del manuscrito, hay aspectos que no puedo comentar aún: en qué momento se incorporó el epígrafe del Alcorán, las fuentes consultadas para la información sobre el teorema perdido de Fermat, la probable búsqueda de los apellidos y las biografías de los dos amigos, las fuentes consultadas sobre el Sudán y la costa del noreste de África. Ya que hay una triple ficha bibliográfica sobre los estudiosos de Dante me parece harto probable que este manuscrito — como otros de la época, como «La secta del Fénix» y «El hombre en el umbral»— tuviera ese aparato crítico en las páginas anteriores. También me imagino que hubo alguna consulta de la Encyclopaedia Britannica y otras fuentes caras a Borges para información sobre esa zona de Cornwall, ya que Pentreath está cerca de minas importantes de cobre y latón; la única mención de Pentreath en la enciclopedia más consultada por Borges está en un artículo sobre los celtas en el que hay una mención de Dolly Pentreath de Mousehole, muerta en el siglo XVIII, la última hablante documentada del idioma celta de Cornwall. De hecho, parte de la zona de Pentreath es ahora un sitio de Patrimonio Mundial de la UNESCO por las minas de los siglos XVIII y XIX (y por restos arqueológicos mucho más antiguos), y se puede ver en la red fotos de grandes ruinas industriales relacionadas a esas minas, algunas de las cuales - como el laberinto del cuentose ubican cerca de acantilados altos sobre el mar. También valdría la pena saber cuáles otras posibilidades barajó Borges para la escueta referencia al «problema del cuarto cerrado» además de los textos mencionados, «The Murder in the Rue Morgue» de Poe (1841) y The Big Bow Mystery de Israel Zangwill (1892): : habrá recordado su polémica con Roger Caillois, quien defendía el origen francés de la ficción policial? ¿Habrá anotado los títulos de $A$ Passage in the Secret History of an Irish Countess de Sheridan Le Fanu (1838) o Le Mystère de la Chambre Jaune de Gaston Leroux (1907)? ¿O textos posteriores a la acción del relato como las novelas de John Dickson Carr (alias Carter Dickson), algunas de las cuales entraron en la serie del Séptimo Círculo que editaba con Bioy Casares para Emecé? Y sin duda tenía a mano uno de sus libros de cabecera, la historia de la Gran Guerra de Basil Henry Liddell Hart, The Real War (1930), después revisado y ampliado como $A$ History of the World War (1914-1918). Es decir, hay mucho que se podría aprender de las páginas que faltan, pero aun así vale la pena trabajar con el fragmento que publicó Miguel de Torre Borges.

Se podría argumentar, como propongo al final de How Borges Wrote, que la relación entre fragmentos y totalidades es de especial interés en el caso de Borges. No solo trabaja de modo imaginativo el problema de la infinitud, o de las infinitudes — piensen en «El Aleph», en «La biblioteca de Babel», en «Tlön, Uqbar, Orbis Tertius», aún en «La casa de Asterión»— sino que su propia obra hace que el lector piense en unidades mucho más grandes o - a veces- infinitas. Ya en «El cielo azul es cielo y es azul» en 1922 escribe: «Todo está y nada es». Ya en «La postulación de la realidad» en 1931 habla de la necesidad que tiene el lector de «imaginar realidades más complejas que las declaradas». Ya en "La biblioteca total» en 1939 interroga la posibilidad de conjuntos grandes (aunque no infinitos) que incluyan todo el saber humano. Sus muchos textos individuales no forman 
totalidades — sus libros son casi todos posteriores a las primeras publicaciones de los textos, y casi siempre menos coherentes de lo que parecen- sino que invitan al lector a que imagine totalidades apenas sugeridas en ellos. En el caso de este fragmento lo que tenemos nos pide que visualicemos lo que falta, y de evocar la imagen del escritor sentándose - primero en Mar del Plata, y un año después en Adrogué- a escribir un cuento que no publicará hasta 1951 y que entrará en El Aleph apenas en su segunda edición en 1952: un período inusualmente largo entre escritura y publicación en Borges, que solía despachar a periódicos o revistas sus escritos apenas los hubiera terminado. Estará cavilando, durante esos varios años, sobre cómo urdir una ficción policial que gire en torno a la identidad y la simulación sin que esa relación se resuelva del todo.

Robó el tesoro y luego comprendió que el tesoro no era lo esencial para él. \{La muerte de Abenjacán era lo esencial. + Lo esencial era que Abenjacán pereciera.\} Simuló ser Abenjacán, mató a

Abenjacán y al fin se convirtió en Abenjacán finalmente fué Abenjacán, es decir un viejo mendigo

escribe en 1948 y 1949. «Lo esencial era que Abenjacán pereciera. Simuló ser Abenjacán, mató a Abenjacán y finalmente fue Abenjacán» (606) publica en 1951 y 1952. La reflexión sobre la identidad personal que había comenzado en 1922 en "La nadería de la personalidad" y que continuaría después en "Borges y yo" en 1957 y en «El otro» en 1974 se presenta con mucha intensidad en este relato, donde la ficción policial está al servicio de la reflexión filosófica e histórica.

\section{Notas}

${ }^{1}$ Cfr. también Singleton 1.186-87.

\section{Referencias bibliográficas}

Alighieri, D. (1980). The Divine Comedy. Trad. y comentario Charles S. Singleton. Princeton University Press.

BALDERSTON, D. (1985). El precursor velado: R. L. Stevenson en la obra de Borges. Editorial Sudamericana. (Segunda edición: Eduvim, 2019.) Balderston, D. (2018). How Borges Wrote. University of Virginia Press. Borges, J.L. (1974). Obras completas. Emecé.

Carlyle, T. (1907). Critical and Miscellaneous Essays. Chapman and Hall. Grabher, C. (1934-36). La Divina Commedia comentata da Carlo Grabher. https://dante.dartmouth.edu

Molloy, S. (1979). Las letras de Borges. Editorial Sudamericana.

Scartazzini, G.A., y G. Vandelli. (1929). Divina Commedia. https:// dante.dartmouth.edu 


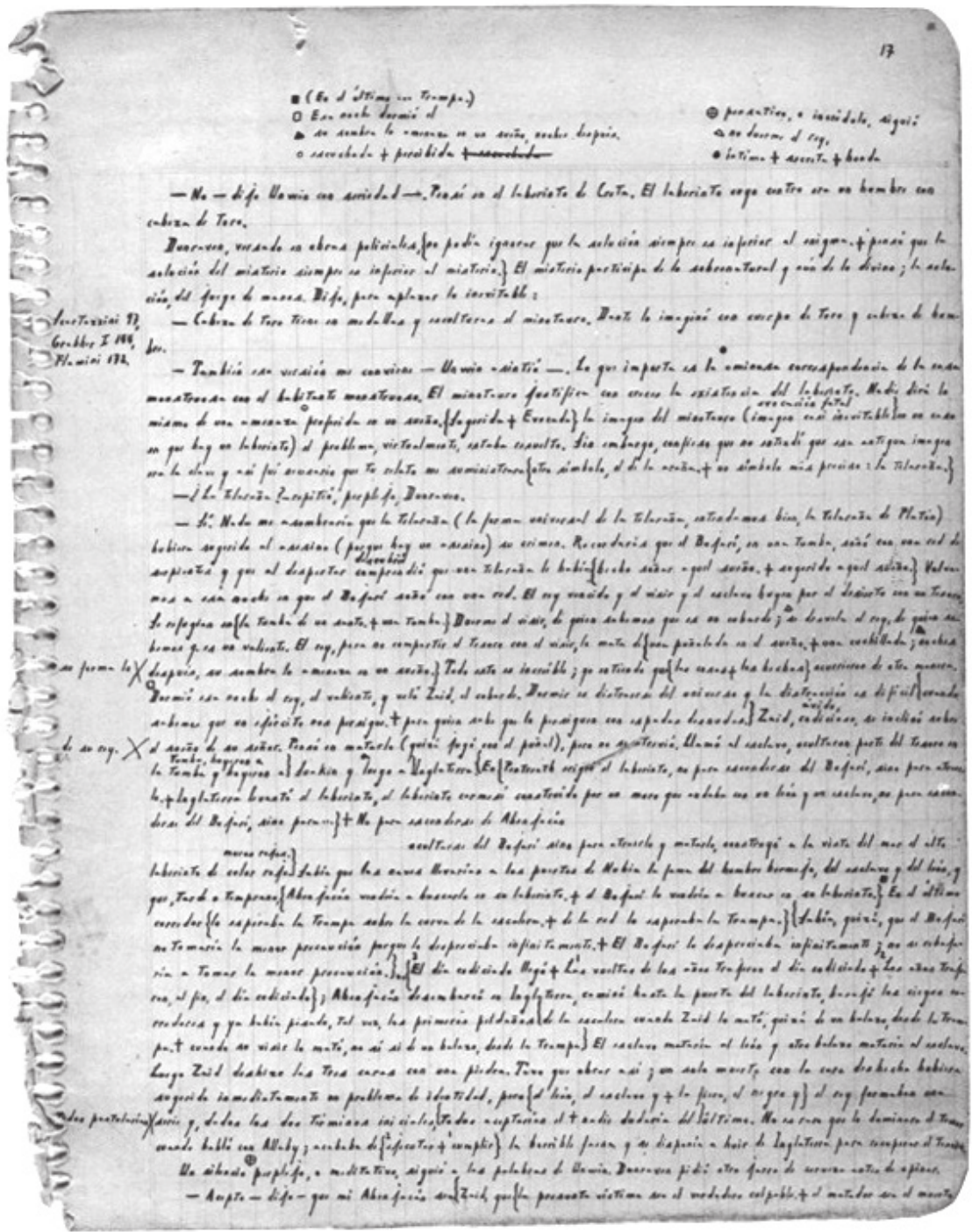




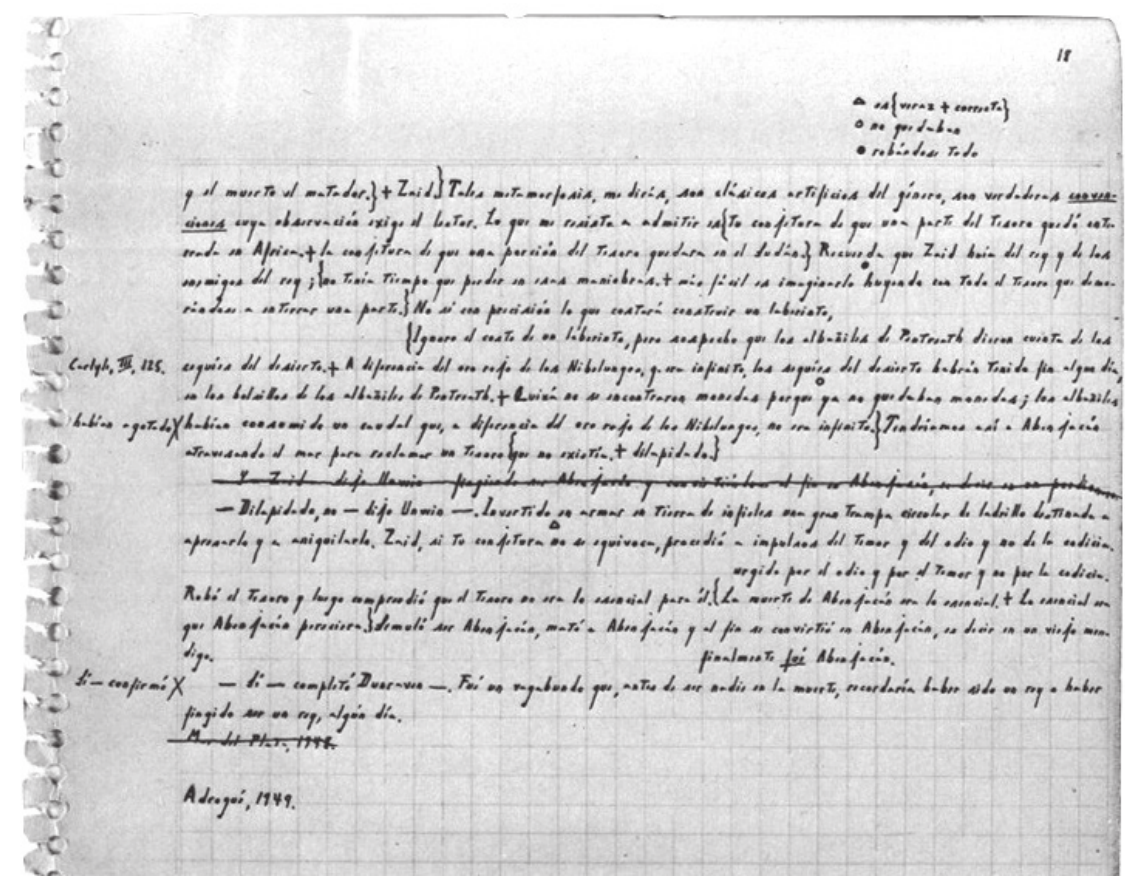

Balderston, Danie

«Genética textual a partir de fragmentos: una página y media del manuscrito de "Abenjacán el Bojarí, muerto en su laberinto" y otros enigmas». El hilo de la fábula. Revista anual del Centro de Estudios Comparados (20), 15-27.
Final de «Abenjacán el Bojarí muerto en su laberinto». Adrogué, 1949.

Fecha de recepción: $15 \cdot 03 \cdot 20$

Fecha de aceptación: $19 \cdot 05 \cdot 20$ 